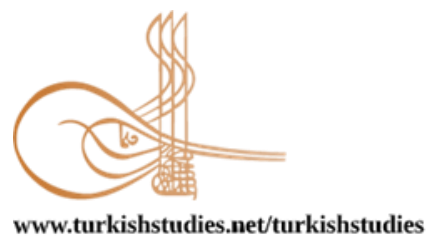

Turkish Studies

\title{
Covid-19 Sürecinde Türkiye'nin İngiltere'ye Malzeme Göndermesinin İngiltere Basınında Yer Alması Üzerine Bir Çalışma
}

\author{
A Study On The Uk Press Coverage Of Turkey's Shipment Of Material To The Uk During The \\ Covid-19 Process
}

\author{
Zülfiye Acar Șentürk* - Rafşan Yağmur Çelik ${ }^{* *}$ - Özgür Can Yolcu***
}

\begin{abstract}
The media is emerging as a developing tool with ideological structures in the historical process. Media texts are seen as an area that contains sovereign rhetoric that reflects ideology. Discourse plays an important role in the development of ideologies, and the dominant ideology retains power through this discourse. The photographs, the language of the news, the headlines used in the newspapers as the written press are mentioned as a situation that expands the dominant ideology. The main problem of working in this context is how the Covid-19 process reflects the news about Turkey's sending aid to the UK. In the research, it was concluded that the problems in domestic policy also affect foreign policy. With the framework created in the news, a frame regarding the mistakes in domestic policy was drawn, while the image of foreign policy was also maintained. It is possible to say that the news produced according to the results obtained from the findings are under the influence of ideologies and presented within a certain framework. Based on the way in which the analyzed news are reflected, newspapers are under the influence of ideology and dominant forces, that they reproduce and make sense of the truth while producing the news, the policy is used actively and biased in the news in the Covid-19 process, whatever the conditions are, the press organizations can use the news for or against the government, It was concluded that they framed the news and presented it to the readers-audience depending on the broadcasting policies. The study is limited from 10 April to 8 May 2020, which includes 30 stories evaluated in the Daily Mail, The Sun, The Telegraph, Mirror, The Guardian, BBC, Independent, Sky News, Express newspapers. Van Dijk's method of news discourse analysis was used to reveal the news language-discourse relationship.
\end{abstract}

\footnotetext{
* Doç. Dr., Uşak Üniversitesi, İletişim Fakültesi, Halkla İlişkiler ve Reklamcılık Bölümü Assoc. Prof., Usak University, Communication Faculty, Public Relations and Advertising ORCID 0000-0003-2606-3547

zulfiye.acar@usak.edu.tr

** Bağımsız Araştırmacı, Kurucu ViaWant London Dijital Pazarlama Danışmanlık Independent Researcher, Founder ViaWant London Digital Marketing Consultancy ORCID 0000-0003-0604-447X rafsanyagmurcelik@gmail.com

**** Doktora Öğrencisi, Kocaeli Üniversitesi, Sosyal Bilimler Enstitüsü, Gazetecilik

Ph.D Student, Kocaeli University, Institute of Social Sciences, Journalism

ORCID 0000-0002-9425-1155

ozgurcanyolcu@gmail.com

Cite as/ Atıf: Acar Şentürk, Z., Çelik, R. Y. \& Yolcu, Ö. C. (2020). Covid-19 sürecinde Türkiye'nin İngiltere'ye malzeme göndermesinin İngiltere basınında yer alması üzerine bir çalışma. Turkish Studies, 15(6), 15-29. https://dx.doi.org/10.7827/TurkishStudies.45376

Received/Gelis: 17 July/Temmuz 2020

Accepted/Kabul: 15 October/Ekim 2020

Copyright (C) MDE, Turkey
} 
Structured Abstract: The media is an instrument that has been developing together with the ideological structures throughout history. The media texts are considered as a field containing the dominant discourses representing the ideology. The discourse plays an important role in the development of ideologies and the dominant ideology holds the power thanks to this discourse. As the printed media, the photos, language of news, and running titles used in the news published in newspapers are accepted to expand the dominant ideology. An example of the main problem within this context is the way in which Turkey's aids sent to England due to the COVID-19 pandemic have been reported in news. The limitation of the study is that the present study examines 30 news published between April 10th and May 8th of 2020 in Daily Mail, The SUN, The Telegraph, Mirror, The Guardian, BBC, Independent, Sky News, and Express newspapers published in England and having different ideologies. The "News as Discourse" analysis method of Van Dijk was used for revealing the relationship between the discourse and the language of news.

The objective of the present study is to reveal how the news on Turkey's aids shipped to England during the COVID-19 pandemic has been reported in the English press. The "News as Discourse" analysis method of Van Dijk was used for revealing the relationship between the discourse and the language of news.

The limitation of the study is that the present study examines 30 news published between April 10th and May 8th of 2020 in Daily Mail, The SUN, The Telegraph, Mirror, The Guardian, BBC, Independent, Sky News, and Express newspapers published in England and having different ideologies.

The null hypotheses of the present study are as follows;

1. In the news examined here, a language criticizing-belittling the Republic of Turkey has been used.

2. In the news examined here, the headlines that are in quotation marks have been used.

3. The aggressive language has been intensively used in the news examined here.

The texts containing the subject of this study were chosen from the news reported between April 10th and May 8th and 30 news about this subject were examined in total. This news are limited to the period during and after aids shipped by Turkey to England. This news was published by Daily Mail, The SUN, The Telegraph, Mirror, The Guardian, BBC, Independent, Sky News, and Express that are the leading newspapers of England and have different ideological perspectives. The news published online by these newspapers were analyzed. These news texts were analyzed within the scope of Van Dijk's discourse analysis in terms of codes represented within the news, headline, words used in the headline, and meanings of these words within the text.

The words used in the texts, the emphases on these words, and the frequency of these words indicate the mental map and ideological structure.

In the analysis sample of Van Dijk, the active-passive, long-short, and simple-complex structure of the sentences were examined in syntactic analysis. Inactive sentence structures, the subject performing the action specified by the verb is clear. In passive sentences, however, it is not important who performs the action specified by the verb. In the headlines analyzed from this aspect, it was found that the sentences used were the active ones. In cases of delay or problematic protective equipment, the active sentences were established over Turkey and personal protective equipment.

Called the art of persuasive speaking, rhetoric includes elements such as metaphors, exaggeration, style, comparison, analogy, etc.

According to the results, the aids provided by Turkey are related to the frame drawn by the media for Turkey. The most frequently used words used in the newspapers examined here were "useless, Turkish health protection equipment, fiasco, vital importance, failure, delay, security standard, crisis, healthcare personnel".

In the present study, it was determined that the right-winger Express newspaper that is against European Union presented the situation as the propaganda of Turkey. Besides those reporting that Turkey used these aids as a propaganda instrument, Daily Mail newspaper made these aids visible. It was also considered as a criticism against the insufficient policies of the government. Then, the news regarding the failure in security test was headlined with the word "fiasco".

In the left-winger newspapers examined here, words such as vital, finally, and NHS worker was frequently used in the headlines. Besides that, as well as emphasizing the "aid" character of them, it was also emphasized that they were procured from a supplier company for a price, and these newspapers found the right-

Turkish Studies, 15(6) 
winger government insufficient. Sky News, which is run by a private company, and BBC that is a public company exhibited a more limited and controlled attitude and paid attention to using a news language containing no interpretation. However, the headline "Sent after the Britons approval" in SKY News isattention-grabbing. In general, the news about the second delivery of equipment and the failure in security tests had a broad repercussion in English media because the delay in the delivery of health protection equipment caused reactions against the government among the healthcare workers. Because of the lack of personal protective equipment, the healthcare personnel had to use plastic bags for their personal protection. Although some sources declared that the delay was due to the supplier between England and Turkey, some of the sources stated that the delay was due to England and a news source reported that the second delivery arrived after the Britons approval.

Keywords: Covid19, Media, Ideology, Discourse Analysis.

Öz: Medya, tarihsel süreç içinde ideolojik yapılar ile birlikte gelişen bir araç olarak karşımıza çıkmaktadır. Medya metinleri, ideolojiyi yansıtan egemen söylemleri içinde barındıran bir alan olarak görülmektedir. Söylem ideolojilerin gelişmesinde önemli bir rol oynamakta ve egemen ideoloji bu söylem sayesinde gücü elinde tutmaktadır. Yazılı basın olarak gazetelerde yapılan haberler içinde kullanılan fotoğraflar, haberin dili, başlıklar egemen ideolojiyi genişleten bir durum olarak belirtilmektedir. Bu bağlam içerisinde çalışmanın temel problemi olarak Covid-19 sürecinde Türkiye`nin İngiltere`ye yardım gönderimi ile ilgili haberlerin nasıl yansıtıldığıdır. Araştırmada iç politikadaki sorunların dış politikayı da etkilediği sonucuna ulaşılmıştır. Haberlerde oluşturulan çerçeve ile hem iç politikadaki yanlışlara ilişkin bir çerçeve çizilirken diş politikaya yönelik olan imaj da devam ettirilmiştir. Bulgulardan yola çıkarak elde edilen sonuçlara göre üretilen haberlerin ideolojilerin etkisi altında kalarak belirli bir çerçeve ekseninde sunulduğunu söylemek mümkündür. İncelenen haberlerin yansıtılma şeklinden yola çıkarak gazetelerin ideoloji ve hakim güçlerin etkisinde kaldığı, haberi üretirken gerçeği de yeniden üretip anlamlandırdığı, politikanın Covid-19 sürecinde de haberlerde aktif ve yanlı olarak kullanıldığı, şartlar ne olursa olsun basın kuruşlarının haberleri iktidarın lehine ya da aleyhine kullanabileceği, kendi yayın politikalarına bağlı olarak haberi çerçevelendirip okucu-izleyici kitlesine sundukları sonucuna ulaşılmıştır. Çalışmanın sınırlılığı 10 Nisan-8 Mayıs 2020 tarihleri arasında İngiltere'de farklı ideolojilerle yayın yapan Daily Mail, The SUN, The Telegraph, Mirror, The Guardian, BBC, Independent, Sky News, Express gazetelerinde değerlendirmeye alınan 30 adet haberden oluşmaktadır. Haber dili - söylem ilişkisini ortaya koymak amacıyla Van Dijk’in haber söylem analizi yöntemi kullanılmıştır.

Anahtar Kelimeler: Covid19, Medya, İdeoloji, Söylem Analizi.

\section{Giriş}

Haber üretiminin inşa sürecinde içeriklerin seçilmesinde ideolojik bakış açısı etkili olmaktadır (Özkır ve Şişman, 2014: 67). Haber bir kurgu olarak görülmekte, dil dolayımıyla aktarılmaktadır. Haber üretilirken, haberi üreten kurum veya kişinin dünya görüşünden, kurumun dünyaya bakış açısından kültürel ve ideolojik yapısından soyutlanmadan haber üretilmektedir (Yağlı, 2007: 356). Yazılı basın içinde sunulan haberler belirli ideolojik söylemin görüşünü yansıtmaktadır. Haberin içinde kullanılan dil, verilen fotoğraf, haber başlıkları, noktalama işaretleri vs. bütün olarak bağlı bulunduğu ekonomik, kültürel yapının ideolojisini barındırmaktadır. Bireylerin içinde bulundukları "toplumsal gerçekliği" anlamlandırmaları büyük ölçüde kitle iletişim araçlarından aldıkları haberler ile ilgilidir. "Haber" olarak adlandırılan bu hikaye anlatım biçimi, bireylerin çevresi ile de ilişki kurmasında önemli bir araç niteliğindedir (İnal, 1996: 135).

İdeolojiler, kendilerini dil ile ifade edip biçimlendirirler. Dili kullananların seçtikleri sözcükler, sözcük öbekleri, konuşma biçimi, anlatımı ve hatta cümle kurma yetileri, söylemin oluşmasında çok büyük etken olduklarından, dilin kullanımıyla söylem oluşur (İnceoğlu ve Çomak, 2009: 35). Haber metinlerini bir söylem olarak ele almak eleştirel haber araştırmaları için haber söylemi analizlerinin temel bir yöntem olarak kabul edilmesini zorunlu hale getirmiştir. Dilbilimin 
yöntemleri ve kavramlarını kullanarak gelişen eleştirel söylem çözümlemesi, haber söylemi analizlerinde toplumsal yapı analizi yapmayı mümkün kılmıştır (Karaduman, 2017: 33).

Haber içinde kullanılan ideolojik dil kamuoyu oluşturmada etkin olarak kullanılan bir yöntem olarak karşımıza çıkmaktadır. Buradan hareketle çalışmada haber söylemi ve inşa edilen ideolojinin ne olduğu açıklanacaktır. Araştırmanın temel problemi olarak ise Covid-19 sürecinde Türkiye nin İngiltere ye gönderdiği yardımlarla ilgili haberlerin yansıtılma şekli ele alınmıştır.

Çalışmanın sinırlılığı 10 Nisan - 08 Mayıs 2020 tarihleri arasında İngiltere'de farklı ideolojilerle yayın yapan Daily Mail, The SUN, The Telegraph, Mirror, The Guardian, BBC, Independent, Sky News, Express gazetelerinde değerlendirmeye alınan 30 adet haberden oluşmaktadır. Haber dili - söylem ilişkisini ortaya koymak amacıyla Van Dijk'in haber söylem analizi yöntemi kullanılmıştır.

\section{Haber ve İdeoloji İlişskisi}

Haber, konusu olduğu alanda bireylerin bilgi edinmesini sağlayan, hayata bakışını değiştirip yönlendiren, gerçekliğin, haberin yayınlandığı aracın bağlı olduğu kuruluşun yapısına, sahip olduğu teknoloji ve üzerinde hâkim olan ideolojiye uygun olarak yeniden kurgulanmasıdır (Rigel, 2000: 177). Bir olayın haber olabilmesi bazı özellikleri taşımasına ya da bazı ihtiyaçlara cevap vermesine bağlı olarak değişmektedir. Bir durumun haber sayılması için sahip olması gereken temel özelliklerin başında konunun ilginç olması ve insan hayatına etkisinin ne denli önemli olup olmadığı gelmektedir. $\mathrm{Bu}$ yüzden bireyler için önemli sayılan insanlar, siyasiler, tanınmış kişiler haberler için takip edilmektedir (Tokgöz, 2000: 227).

"Haber, olayın, olgunun kendisi değil ama belli bir süreç içinde, belli kriterlere göre seçilen ve yine belli bir süreç içinde belli kriterlere göre sunulan olgudur. Bu seçim ve sunum süreci haber değerlerinin önemini vurgulamamızı zorunlu kılar. İlginç olan olaylar haberdir" (İnal, 1994:137). Buradan hareketle haberlerin seçiminde belirli kriterler olduğunu, haberin olgulardan oluştuğunu, seçim ve sunumla bir süreç olduğunu, haber yazımında değerlerin esas alındığını ve ilginç olayların haber olabileceğini söylemek mümkündür.

Haber özetle, dünyanın farklı yerlerinden ortaya çıkan olaylar, şeyler ya da kişiler hakkındaki en son ve en güncel enformasyondur. Haberin temel fonksiyonu bilgi vermektir. Enformasyon ise yaygın bir tanımla haberle birlikte bireylere aktarılan bilgidir (Erdoğan, 1997: 252).

Bireylerin merak duygusu onları yaşadıkları çevre, ülke ve dünyada neler olduğu ile ilgili bilgi almaya yöneltmektedir. Bilginin sistematik biçimde elde edildiği haberler ise aktarılırken seçilmekte, değiştirilmekte ve yeniden oluşturulmaktadır. Haberin medyada yer alıp almayacağı, alacaksa ne biçimde yer alacağı birçok karar süzgecinden geçerek ortaya çıkmaktadır. Bunların başında ise; medya patronları, siyasal iktidarlar, gazetecilerin değer yargıları gelmektedir. Dolayısıyla habercilik alanı herkesin söz sahibi olup etkisini göstermek istediği bir alandır. Haberlerin oluşmasında önyargılar, kişisel ve kurumsal çıkarlar, siyasi seçimler belirleyicidir. Bu kadar etkenin bir arada olması ve hangisinin etkisinin daha çok olacağının zamana ve duruma göre farklılık göstermesi de gerçeklerin aktarılırken aslından uzaklaşıp değişmesine, kırpılmasına hatta çarpıtılmasına neden olmaktadır (Çaplı, 2002: 81). Buradan hareketle haberde gerçeğin aktarıldığ boyutlar, bu süreçte dışarıda bırakılan öğeler ve vurgulanarak ifade edilen kısımlar ideolojik tercihlerin sonucudur. Bunu yaparak gerçekliği inşa eden haberin gerçeği ilettiği de iddiadan öte değildir. Aslında yapılan haberin ideolojik rolünün gizlenmesidir (Arık, 2009: 247). Tarihten bugüne farklı biçimlerde kaynaktan hedefe bir biçimde ulaşmış olan olayın hakkındaki bilgi ya da enformasyon yine tarihten bu yana bu olayın gerçekleşmesinde rolü olan ya da bu olay duyulduğunda herhangi bir sebepten dolayı rahatsız olacak olan güç sahiplerini rahatsız etmiştir (Bulut, 2020: 729).

Benzer şekilde Fairclough, metinlerin okuyucunun yorumu olmadan anlamının eksik kaldığını savunmaktadır. Van Dijk ise, metni yorumlamanın konuyla ilgili olarak öncesinde edinilen

Turkish Studies, 15(6) 
bilgiye bilgiyle gerçekleştiğini belirtse de haber medyasının birincil derecede etkili olduğu alanlar olduğunu, bunların başında da sosyal ve politik olayların yorumlanması ile bazı inançların yerleşmesinin geldiğini ifade etmektedir (Ülkü, 2004: 384).

İdeoloji medya çalışmalarında medya için üretilen mesajların anlamlarında yer almaktadır. Anlamın biçimlenip sabitlendiği yer ise hegemonik mücadeledir. İdeolojilerin söylem alanında yaptıkları ise, medya metinlerinde yer alan çok vurgulu anlamları kendi çıkarlarına hizmet edecek biçimde tek vurgu etrafinda sabitlemek için mücadele içinde olmalarıdır (Dursun, 2001: 56). Böylece haber dış müdahalelerden etkilenmiş bir biçimde ortaya çıkmaktadır. Müdahale edilmiş haberlerin insanların düşüncelerini belirli bir yönde etkilemesi kaçınılmazdır. Bu da haber aracılığıyla gerçeğin yeniden inşa edilmesini sağlayan ideolojik bir boyuttur (Özerkan, 2002: 70). İdeoloji söylemsel pratiklerle ilişkilendirildiği için yapısı gereği simgeseldir. İdeoloji söylemin nasıl olacağını belirleyip, ona sınırlar çizen mantığı ortaya çıkarırken, söylem de ideolojinin sürekli olarak üretildiği ve yeniden üretildiği alandır. Bundan dolayı, bir durumun ideolojik yapısı incelenirken onu oluşturan söylemsel pratiklerin incelenip çözümlenmesi gerekmektedir (Mumby, 2004:138).

Bu yönüyle medya, egemen ve ayrıcalıklı grupların gündeminde olan ekonomik, siyasal ve toplumsal gündemlerini topluma aktarıp onları hâkim güçler lehine yönlendirerek bu görüşleri savunmayı toplumsal bir amaç olarak görmektedir. Amacını gerçekleştirmek için de haber olacak konuların ve üzerinde konuşulacak konuların seçilmesi, bilgilerin süzgeçlerden geçirilerek değerlendirilmesi ya da yok sayılması ve hangi sınırlar çerçevesinde ele alınacağını, neyin ön plana çıkarlıp, hangi tonda ifade edileceğine karar vermekte, bu kararlara ideolojinin müdahale etmesine imkân tanımaktadır (Herman ve Chomsky 1998: 100). İletişimin hiçbir şeklinin tamamen tarafsız olması mümkün değildir. $\mathrm{Bu}$ durumda gazetecilerin de tarafsız olmasını beklemek zor görünmektedir. Haberciler metinleri oluştururken kendi inanç ve ideolojilerini sürece dahil etmektedirler. Medya kuruluşlarının belirli bir ideolojinin etkisinde kalması bazı toplumsal ve siyasi konuları ön plana çıkarmalarına neden olmaktadır. Muhabirler de olayları kamuoyu için üretirken, duruma yeniden anlam yüklemektedirler. Yorumlar, böylece anlamları oluşturur hale gelmektedir. Haberin yayınlanmış hali gerçekten ziyade yorumlanmış şeklidir. Medya olayları, toplumsal yaşamı yeniden üreterek dönüştürür. Her metin gerçekmiş gibi görünse de aslında olan gerçeğin değiştirilmiş halidir. Metinlerin inşa edilmesi dikkatin istenilen konuya istenilen biçimde çekilmesidir. Haberler de buna göre oluşturulur. Medya gerçekliği kendi ideolojisine göre tanımlamaktadır (Burton, 1995).

Egemen iktidarlar medyayı da kullanarak kendisini meşrulaştırmaktadır. Bunu da "kendisine yakın inanç ve değerlerin tutunmasını sağlayarak, bu inançları, doğrulukları kendinden menkul ve görünüşte kaçınılmaz kılacak şekilde doğallaştırarak ve evrenselleştirerek, kendisine meydan okumaya kalkışan fikirlere çamur atarak, rakip düşünce biçimlerini, muhtemelen, açığa vurulmayan, ama sistemli bir mantıkla, dışlayarak toplumsal gerçekliği kendine uygun yollarla çapraşıklaştırarak" yapmaktadır (Eagleton, 1996: 23). Güçlü ve baskın medya kuruluşları toplumdaki etkili çıkar gruplarının güdümünde ve onların uzantıları şeklinde faaliyetlerini sürdürmekte, egemen ideolojinin yeniden üretilmesinde ve kontrol mekanizmasının aktif olarak işlemesi için gereken rutinleri, değerleri ve kurumsal yapıları bir arada tutmaktadır. Medyanın rutinleri güçlü ve egemen olanların lehinde uygulanmaktadır (Shoemaker ve Reese, 1997:103).

Medyanın seçtiği haberlerin toplumun ilgisini istenildiği yöne çekebilmesi için çağrışımlar kullanılmaktadır. Bunun yanında haberin anlamlı hale gelmesi için içeriğe nelerin dahil edileceği, nelerin göz ardı edileceğini belirlemek için çerçevelemeden faydalanılmaktadır (Yüksel ve Gürcan 2005: 98, Atabek ve Uztuğ 1998: 100). Haber çerçevelemede esas olan ise haberin hangi açıdan sunulacağının belirlenmesidir. Haber bir yayın kuruluşu için olumlu özellikleriyle ön plana çıkarken, başka bir yayın kuruluşu için olumsuz yanlarıyla gösterilmektedir. Haberin malzemesi aynı olsa da çerçevelenme şekli habere izleyicinin bakışını ve yorumunu değiştirmektedir. Çerçeveleme insanların bir konunun kendilerine sunulmuş haliyle bilgi sahibi olmalarını veya bir konu hakkındaki 
düşüncelerinin yeniden yönlendirildiği süreci ifade eder (Chong ve Druckman, 2007:106). Çıkar grupları, siyasetçiler ve gazeteciler medyanın gündemini çerçevelerini şekillendirmekte, belirli bir konuyla ilgili haber mesajlarının hacmi ve niteliği üzerinde etkili olmaktadırlar (Scheufele ve Tewksbury, 2007:12). Haberlerin sunum biçimleri de yine yayın kuruluşlarının bağlı oldukları kurumların siyasi ve ekonomik yapısından etkilenmektedir. Haberlerin içeriğini farklı şekillerde yansıtan gazeteler haberlere verdikleri önem sıralamasını da buna göre belirlemektedir (Şentürk Acar ve Tos, 2018:101). Medya kuruluşları, sürekli olarak tutarlı bir ideoloji ile toplumsal yapıyı düzenlemektedirler. Bu amaçla bir dizi ortak değerler ve mekanizmalar üreterek toplum üzerinde hegemonya kurmaktadırlar (Shoemaker ve Reese 1997: 116). Oysa dördüncü güç kabul edilen medyaya bu gücü verenlerin başında medyanın kamu yararını esas alması gelmektedir. Normal şartlarda basının kamuoyu adına iktidarı denetlemesi gerekirken, iktidarlar basın aracılığıyla kamuyu denetlemekte ve basının kamuoyu oluşturma özelliğinden faydalanarak meşruiyetlerini sağlamaktadırlar.

Bunun yanında medyanın gücünün bireylerin dünya görüşlerini şekillendirebilecek, sahip olunan düşünce kanaatlerin oluşmasında belirleyici olacak kadar yoğun olduğunu ve düşünce ile davranış biçimleri üzerindeki etkisinin giderek arttığı da bir gerçektir. Haberler, bireyleri etkileyip yönlendirmede önemli bir işleve sahiptir (Burton 1995:14). Haber metinlerinin egemen ideolojinin meşruiyetini sağlamasında haber metinlerinin oluşturulmasındaki faktörler de etkilidir. Bunlar (İnal, 1996: 95-96):

Haberin söylemi, gazeteciliğin günlük pratikleri içerisinde oluşur.

Haberin söylemi, gazetecilerin profesyonel ideolojileri içinde oluşur. Diğer bir deyişle basının ticari bir işletmeye dönüşümü ve daha sonra oluşan yatay ve dikey tekelleşme olgusu ile birlikte gelişen gazetecilik normları söylemi biçimlendirir.

Haberin söylemi, haber metinlerinin üretildiği somut tarihsel koşullar ve üretim anı ile belirlenir. Toplumsal formasyon içinde kesitsel olarak oluşan siyasal, ekonomik güç/iktidar ilişkileri metinlere yansir.

Haberin söylemi medyanın ekonomi politikası içinde yapılanır.

Nedeni ne olursa olsun haber metinleri belirli bir ideolojiye göre hazırlanmakta, konuların istenilen yönleri ortaya çıkarılırken diğer yönleri çerçevenin dışında bırakılmaktadır.

\section{Söylem olarak Haber}

Söylem kavramı dilin bir ürünüdür ve içerdiği anlamlar nedeniyle basit bir konuşma ve ifadeden farklıdır. Söylem kavramının felsefe, siyaset, iletişim gibi alanlarda kullanılmasına bağlı olarak farkı anlamlar yüklenerek tanımlanması yapılmıştır. Söylem, dilbilimsel çalışmalar açısından konuşan kişi tarafından gerçekleştirilen dile, dilin eylemsel haline işaret etmektedir. Buradan hareketle söylem, cümlelerin oluşturduğu birimdir ve mesajı oluşturan ögelerin toplamından oluşan bir bütündür (Bilgin, 2003: 360). Söylem kavramı, sosyal bilimlerde kullanılan söylem analizi yöntemi kavramının da ortaya çıkmasına neden olmuştur. Söyleme göre dil gerçekliği üretir, gerçeği yansıtmaz. Dil sözcüklerin anlamının belirleyicisidir. Nesneler anlamın üretilmesinde etkili değildir. Yap1, anlam üretimini gerçekleştirmektedir ve dil anlamın merkezidir (Erdoğan ve Alemdar, 2010: 323).

Bilginin, gücün, ideolojinin dildeki kullanımı birer eylemdir ve bunların işlevsel olarak etkin olması söylem içinde anlamlı bir şekilde yer almasıyla mümkündür. Gündelik konuşmalar içinde anlamsızmış gibi değerlendirilen ifadeler bile bir söylem olarak değerlendirildiğinde anlam ifade etmektedir (Sözen, 1999:13). Söylemsel ve zihinsel olarak kontrol edebilme, uygulayan kişiye hegemonya ve hakimiyet kazandırmaktadır. Bu nedenle mesajı alanların söylemi gerçekleştirenlerin otorite sahibi ve güçlü olduğu yönünde bir algıya sahip olmaları gerekmektedir. Toplumların yapısı 
ve özelliklerine göre bireylerin ya da grupların söylemleri güçlü ya da güçsüz, etkili ya da etkisiz olarak değerlendirilmektedir (Devran, 2010: 29). Haber kaynağının kamuoyu gözündeki algısı da haberin etkili olup olmadığını belirlemektedir. Bireyler kendileri için anlam ifade eden bir yayın kuruluşundan aldığı haberi doğru ve etkili olarak kabul ederken, diğeri için aynı haberin bir anlamı olmayabilir. İdeolojik olarak aynı düzlemde bulunmak haberin etkisini arttıracağı gibi, aksi durumda da azaltmaktadır.

Haberler de diğer kurgusal metinler gibi içerisinde söylem barındırmaktadır. Bu söylemle haberle aktarılan olaylar/gerçekler yeniden canlandırılmaktadır. Öte yandan haberde yer alan egemen söylemler doğal hale gelmektedir. Bunun sonucu olarak yeniden oluşturulan egemen ideolojiye ek olarak anlatıcı da haberleri kurgulamaktadır. Gazetelerde haberin aktarılmasını sağlayan başlıklar, fotoğraflar, alt başlıklar, cümleler, spotlar gibi tüm unsurlar haberde hâkim ideolojiyi yansıtacak şekilde kullanılmaktadır. Tüm bunlara ek olarak haber hâkim sınıfın görüşlerini aktaran bir araç olmasının yanında söylem olarak da diyalog işlevi görmektedir (Tokgöz, 2000: 161-162).

Haber, haberi yazan kişinin bireysel müdahalesine tamamen izin vermediği için edebiyat, sinema ve televizyon dizilerinden farklı özellikleri olan bir söylem türüdür. Gazetecinin haberin oluşturulmasında ideolojik yapı, kurumsal kodlar ve başka faktörler de etkilidir. Haberlerin söylemsel yapısında iktidar/güç sahibi kişi ve kurumların etkisiyle haberlerde tarafsızlık, nesnellik gibi kavramlarla da denge sağlanılmaya çalışılmaktadır. Tüm bunların etkisinde haberciler, habere konu olan olayın çerçevelenmesinde belli görüşlerin egemen konumda olmasına da özen göstermektedirler (İnal, 1994: 142).

\section{Araştırmanın Problemi}

Çin'in Wuhan şehrinde ortaya çıkıp küresel bir tehlike haline gelen Covid-19, sadece 19181919 Büyük Influenza Pandemisi’nden sonra en ciddi küresel sağlık krizi değil, aynı zamanda yakın tarihin en yüksek maliyetli pandemisi özelliğini taşımaktadır. Bu özelliğinin yanısıra Covid- 19, küresel bazda ortaya çıkan büyük krizlerden önemli şekilde farklılıkları da içinde barındırmaktadır. Birçok ülke birden fazla krizle karşı karşıya kalmıştır: Sağlı krizi, finansal kriz ve birçok karmaşık fiyatlarda etkileşim içinde olan emtia fiyatlarında bir çöküş şeklinde yaşanmıştır (Bingül, Türk, Ak, 195:2020). Araştırmanın da temel problemi bu yaşanan sağlık krizinde ideolojiyi yansıtan bir araç olarak kullanılan gazetelerin İngiltere'de farklı ideolojiler içinde yayın yapan gazetelerin Covid-19 sürecinde İngiltere ye yardım gönderimi ile ilgili haberlerin nasıl yansıtıldı̆̆ı̆ır.

Çalışmanın araştırma soruları şu şekildedir;

1. Haber içerikleri hangi algılama kodları oluşturularak kurgulanmıştır?

2. Haber içeriklerinde aktarılan gerçeklik biçimi ne şekilde aktarılmıştır?

3. Haberlerde yer alan söylem nasıl işlenmiştir?

\section{Araştırmanın Amaç ve Yöntemi}

$\mathrm{Bu}$ çalışmanın amacı Korona virüs (Covid19) salgınında Türkiye'nin İngiltere'ye yaptığı tıbbi koruma malzemeleri yardımıyla ilgili haberlere İngiltere basınında nasıl yer verildiğini göstermektir. Haber dili- söylem ilişkisini ortaya koymak amacıyla Van Dijk'in haber söylem analizi yöntemi tercih edilmiştir.

Söylem analizi, haber içeriğini kendi bağlamından ayırmadan inceleme amacı taşıyan bir tekniktir. Söylem analizi yöntemi, iktidarlar var olan ilişkilerini, toplumda yer alan önyargıların haber söylemi içerisinde nasıl yer aldığını açıklamaya yönelirken bu ilişkilerin eleştirilmesinden de yola çıkar (İnal, 1996: 96).

Van Dijk'in söylem analiz yönteminde incelenen metinler makro ve mikro yapılar olarak ikiye ayrılır. Makro yapı; kendi içerisinde tematik yapı ve şematik yapı olarak ayrılırken mikro yapı ise şematik çözümleme, bölgesel uyum, kelime seçimleri ve haber retoriği olarak ele alınmaktadır 
(Arık, 2009: 248). Teun Van Dijk, haberi bir tür olarak değil, bir söylem olarak ele almakta, haberin söyleminin toplumda var olan egemen söylemlerin bir ürünü olarak görmektedir. Eleştirel söylem çözümlemesi yöntemini kullanan Van Dijk, haber söylemi incelemelerinde haberi makro ve mikro yapılarına göre incelemektedir.

Gazete haberlerinde haberin makro yapısını, başlık, alt başlık, fotoğraf, ayrı puntolarla yazılan spotlar ve haber girişleri oluşturur. Hiyerarşik bir yapıyı takip eden haberin yapısı, bu şema tarafından organize edilmektedir. Makro yapı çözümlemesinde başlıklar, haber girişleri, ana olay, haber kaynakları, ardalan ve bağlam bilgisi gibi unsurlar ele alınmaktadır.

Haber metinlerinin mikro yapılarını oluşturan ise, sözcük seçimleri ve cümle yapıları (sentaks) dır. Ayrıca haberin ikna yolları yani retoriği, arka arkaya gelen cümleler arasında kurulan ilişkiler de mikro yapısal özellikler arasında yer almaktadır. Haberin mikro yapısal özellikleri söylemin kurulmasında önemli bir işleve sahiptir (van Dijk,1988:19-38; 2007:170). Bu analiz yöntemi, var olan iktidar ilişkilerinin ve toplumda yer alan önyargıların söylem içinde nasıl kurulduğunu açıklamaya yönelirken aynı zamanda bu ilişkilerin eleştirilmesinden yola çıkar. Öte yandan kaynaklarla bağlantı, mülakatlar, sunumlar, alıntılar, egemen konu başl1kları, çağrışımlar, haber yazma üslubu gibi unsurları, birçok toplumsal ve ideolojik konumu içinde taşır ve dolayısıyla haber üretiminin örtülü bir yanlılık taşımasına yol açan unsurlarını ortaya çıkarır (Şeker' den akt. Toruk ve Sine, 2012: 359). Araştırmada da Teun A. Van Dijk tarafindan geliştirilen makro yapısal analiz formülasyonundan tematik yapı içerisindeki başlıklar ve mikro yapısal analiz kısmından ise kelime seçimlerinden yararlanılmıştır.

\section{Araştırmanın Evrem ve Örneklemi}

Çalışmanın evreni; İngiltere'de farklı ideolojik bakış açılarıyla yayın yapan günlük gazetelerdir. Bu gazetelerin seçilme nedeni farklı ideojilere sahip olarak İngiltere'de yaşanan sağlık krizine karşı Türkiye'nin yapmış olduğu yardımları sunuş biçimleridir. Çalışmanın örneklemini ise; Daily Mail, The SUN, The Telegraph, Mirror, The Guardian, BBC, Independent, Sky News, Express gazeteleri oluşturmaktadır.

\section{Araştırmanın Sınırlılıkları}

Çalışmanın sınırlılığı 10 Nisan-8 Mayıs 2020 tarihleri arasıyla sınırlı tutulmuştur; çünkü Türkiye'nin İngiltere'ye gönderdiği yardımlar ile ilgili haberler bu tarihler aralığında yapılmıştır. İngiltere'de farklı ideolojilerle yayın yapan Daily Mail, The SUN, The Telegraph, Mirror, The Guardian, BBC, Independent, Sky News, Express gazetelerinde değerlendirmeye alınan 30 adet haberden oluşmaktadır.

\section{Araştırmanın Varsayımları}

Araştırmanın temel varsayımları şu şekildedir;

Çalışmada ele alınan haberlerde Türkiye Cumhuriyeti devletini eleştiren- küçümseyen dil kullanarak haber yapılmaktadır. Gazeteler, olayları kendi ideolojik yapılarına göre yansıtmaktadır. Çalışmadan incelenen haberde çatışmacı dil yoğun olarak kullanılmaktadır.

\section{Haber Metinlerinin Makro ve Mikro Yapıya Göre Çözümlenmesi}

Araştırmanın amacını taşıyan metinler 10 Nisan ve 08 Mayıs tarihleri arasında yayımlanan haberlerden seçilmiş ve konuyla ilgili toplam 30 haber incelenmiştir. Bu haberler Türkiye`nin İngiltere ye gönderdiği yardımlar ve sonrasında yayımlanan haberlerle sınırlıdır. Ele alınan haberler ise; haberlerin sunuş biçimlerini inceleme açısından İngiltere'nin belli başlı basın yayın organlarından Daily Mail, The SUN, The Telegraph, Mirror, The Guardian, BBC, Independent, Sky News, Express'de yayınlanan haberlerdir. Gazeteler, yapıları itibarıyla farklı ideolojilere sahiptir. Bu basın organlarında yer alan haberler, haber içeriklerinde sunulan kodlar, haber başlığ 1 , başlıklarda 
seçilen kelimeler ve bu kelimelerin metin içerisinde nasıl kullanıldığı açısından Van Dijk söylem analizinde yer alan kurallar çerçevesinde irdelenmiştir.

\section{Tematik Yapı: Başlıklar}

10 Nisan ve 08 Mayıs 2020 tarihleri arasındaki haber metinlerinin başlıkları şu şekildedir;

1. 'Karanlığın ardında nice güneşler var.' Türkiye, şiir yazılı kutularda acil koruyucu maske ve önlük de dahil olmak üzere Birleşik Krallığa yardım gönderiyor (Daily Mail, 10.04.2020).

2. Türkiye İngiltere`ye maske ve önlük dahil kişisel malzemeler için koronavirüs 2 . yardım uçağı gönderiyor (Daily Mail, 11.04.2020).

3. 400.000 önlük malzeme seti bugün Türkiye'den geldi ancak Robert Jenrick (Yerel yönetimlerden sorumlu devlet bakanı) Matt Hancock`ın (Sağlık ve Sosyal Bakım Dışişleri Bakanı) NHS çalışanlarının ürünlerin ‘tükenmesinden` sonra YENIDEN KULLANMA açıklanması için öfkeli olduğunu söyledi (Daily Mail, 18.04.2020).

4. Yardım Eli: Türkiye on safhadaki sağlık görevlilerine yardımcı olmak için İngiltere'ye acil durum ekipmanı gönderdi (The SUN, 10.04.2020).

5. KIŞiSEL KORUYUCU REZALETİ Royal Air Force umutsuz sağlı çalışanları için Türkiye den yola çıkan hayati öneme sahip malzemelerin gelişi günler sürebilir (The SUN, 20.04.2020).

6. KORUMA \& HIZMET: Türkiye' den kişisel koruma malzemeleri geldi mi? (The SUN, 21.04.2020).

7. FIYASKO DEVAM EDIYOR Türkiye'den getirilen'Kullanışsı' coronavirüs sağlık malzemeleri NHS sağlık testlerini geçemediğinden EL KONULDU (The SUN, 07.05.2020).

8. Ulusal Sağlık Sistemi için hayati önem taşıyan malzemelerin uçuşu ertelendi (The Telegraph, 19.05.2020).

9. Royal Force uçağı Türk tedarikçi anlaşması krizi yüzünden bekliyor (The Telegraph, 22.04.2020).

10. Birkaç saatte Türkiye'den gelebilecek olan yeterli miktardaki kişisel sağlık koruma malzemeleri gecikti (The Telegraph, 23.04.2020).

11. Özel kaynak: Royal Air Force ile Türkiye'den getirilen sağlık koruma malzemeleri 'kullanışsı' bulundu (The Telegraph, 06.05.2020).

12. 'Fiyasko' NHS için istenen kişisel sağlık malzemeleri gecikti (Express, 19.04.2020).

13. Türkiye 'den sağlık koruma malzemeleri NIHAYET büyük bir propagandayla ulaştı (Express, 22.04.2020).

14. 'Işse yaramaz.' Türkiye 'den gönderilen 400.000 sağlık önlüğüne hükümet el koydu (Express, 07.05.2020).

15. Başarısızlığa karşı Hayatı öneme sahip sağlık koruma kitleri için doktorların talepleri cevaba ulaşıyor (Mirror, 19.04.2020).

16. 84 tonluk NHS işçileri için Türkiye'den gelen koruyucu alet kargosu ertelendi (Mirror, 19.04.2020).

17. Türkiye`den gönderilen kişisel sağlık koruma malzemelerinde fiyasko, onlar kullanılamaz (Mirror, 07.05.2020).

18. Hayatı öneme sahip 400.000 önlük dahil kişisel sağlık koruma malzemeleri İngiltere'ye gelişte gecikme (The Guardian, 19.04.2020). 
19. Türk Sağl1k Koruma Malzemeleri nihayet İstanbul havaalanından İngiltereye doğru yolda (The Guardian, 21.04.2020).

20. Bakan onayı ile Türkiye 'den gelen sağlık koruma malzemeleri İngiltere ye indi (The Guardian, 22.04.2020).

21. Kişisel sağlık koruma siparişi \%10`dan az depozitle İngiltere`de (The Guardian, 23.04.2020).

22. Hükümet, 400,000 Türk önlüklerinin NHS için kullanışsız olduğunu onayladı (The Guardian, 23.04.2020).

23. 'İngiltere Pazar günü sadece Türkiye'den koruyucu malzeme sordu' sonra doktorlara yolda olduğunu söylediler (Independent, 21.04.2020).

24. Türkiye 'den getirilen önlükler hükümetin son dakika stratejileriyle 'kullanışsı' bulundu (Independent, 07.05.2020).

25. Royal Air Force Türkiye ye NHS malzemelerini almak için indi (BBC, 20.04.2020).

26. Royal Air Force Türkiye`den Türk Sağlık Koruma Malzemeleri ile İngiltere'ye indi (BBC, 22.04.2020).

27. Coronavirüs Kişisel Koruma Ekipmanı: Türkiye'den sipariş edilen önlükler güvenlik stardantlarını geçemiyor (BBC, 07.05.2020).

28. İngiltere sadece Türkiye`den Pazar günü yardım istedi, Britons (ingilizler) onayı sonrası yola çıtı (SKYNews, 21.04.2020).

29. Ulusal Sağlik Sistemi için hayati önem taşıyan malzemelerin uçuşu ertelendi. (SKYNews, 21.04.2020).

30. Türkiye'den gönderilen sağl1k koruma malzemeleri güvenlik standartlarına uymuyor. (SKYNews, 08.05.2020).

\section{Sentaktik Yapı: Kelime Seçimleri}

Metinlerde yer alan sözcükler, bu sözcüklere yapılan vurgular ve hangi sözcüklerin daha sık kullanıldığı zihinsel haritayı ve ideolojik yapıyı göstermektedir.

\section{Cümle Yapıları}

Van Dijk'in çözümleme modelinde sentaktik çözümleme yapılırken cümlelerin uzun- kısa, basit-karmaşık, aktif-pasif durumları incelenmektedir (Van Dijk, 1988, 71). Aktif cümle yapılarında yüklemi yapanın kim olduğu açıktır ve özne olarak ifade edilmektedir. Pasif cümle yapılarında ise fiili yapan yüklemi yapanın kim olduğunun önemli olmadığı cümlelere pasif cümle denilmektedir. $\mathrm{Bu}$ doğrultuda incelenen haber başlıklarında cümleler aktif cümle yapısına sahiptir. Gecikme, koruma malzemelerinin sorunlu çıkmasında özne durumunda Türkiye ve kişisel koruma malzemeleri üzerinden aktif cümleler kurulmuştur.

\section{Büyük harfle kullanılan kelimeler}

- YARDIM ELİ (The SUN, 10.04.2020)

- YENIDEN KULLANMA (Daily Mail, 18.04.2020)

- KIŞSiSEL KORUYUCU REZALETİ (The SUN, 20.04.2020)

- FİASKO DEVAM EDIYOR (The SUN, 07.05.2020)

- NIHAYET (Express, 22.04.2020)

- EL KONULDU. (The SUN, 07.05.2020)

Tırnak içerisinde kullanılan kelimeler

- 'Karanlığın ardında nice güneşler var. ' (Daily Mail, 10.04.2020) 
- ‘tükenmesinden` (Daily Mail, 18.04.2020)

- 'Kullanışsı' (The SUN, 07.05.2020)

- 'Kullanışsız' (The Telegraph, 06.05.2020)

- 'Fiyasko' (Express, 19.04.2020)

- 'İşe yaramaz.' (Express, 07.05.2020)

- ‘\%10`dan az`(The Guardian, 23.04.2020)

- 'İngiltere Pazar günü sadece Türkiye'den koruyucu malzeme ' (Independent, 21.04.2020)

- 'kullanışsı’ (Independent, 07.05.2020)

Sıklıkla kullanılan kelimeler

- Kullanışsız, Türk Sağlık Koruma Malzemeleri, Fiyasko, Hayatı önem, Başarısızlık, Erteleme, Gecikme, Güvenlik Standarttı , Kriz, Sağlık Çalışanları

\section{Vurgulanan kelimeler}

- Şiir yazılı kutular (Daily Mail, 10.04.2020).

- Hayatı öneme sahip malzemeler (The Telegraph, 19.04.2020).

- İngiltere'ye gelişte gecikme - Hayatı öneme sahip (The Guardian, 19.04.2020).

- Başarısızlığa karşı hayatı öneme sahip sağlık koruma kitleri (Mirror, 19.04.2020).

- Koruyucu alet kargosu ertelendi. (Mirror, 19.04.2020).

- Koruyucu alet kargosu ertelendi. (Mirror, 19.04.2020).

- Hayatı öneme sahip malzemeler (The SUN, 20.04.2020).

- Türk Sağllk Koruma Malzemeleri nihayet (The Guardian, 21.04.2020).

- İngiltere ye gelişte gecikme (The Guardian, 21.04.2020).

- Türk tedarikçi anlaşması krizi (The Telegraph, 22.04.2020).

- Büyük bir propagandayla ulaştı. (Express, 22.04.2020).

- Sadece birkaç saatte (The Telegraph, 23.04.2020).

- Sağl1k önlüğüne hükümet el koydu (Express, 07.05.2020).

- Kişisel sağlık koruma malzemelerinde fiyasko (Mirror, 07.05.2020).

- Hükümetin son dakika stratejileriyle (Independent, 07.05.2020).

\section{Retorik Ardalan}

Söz söyleme sanatı olarak adlandırılan retorik icerisinde metaforlar, abartmalar, üslup karşılaştırma ve benzetme gibi unsurları taşımaktadır.

Haber başlıklarındaki retorik ardalan şu şekildedir;

- 'Karanlığın ardında nice güneşler var. 'Türkiye, şiir yazılı kutularda acil koruyucu maske ve önlük de dahil olmak üzere (İroni) (Daily Mail, 10.04.2020).

- NHS çalışanlarının ürünlerin 'tükenmesinden' sonra YENIDEN KULLANMA açıklanması için öfkeli olduğunu söyledi (Abartı) (Daily Mail, 18.04.2020).

- Yardım Eli: (İroni) (The SUN, 10.04.2020).

- KISSiSEL KORUYUCU REZALETİ Royal Air Force umutsuz sağlik çalışanları için Türkiye`den yola çıkan hayati öneme sahip malzemelerin gelişi günler sürebilir (Eleştiri- Küçümseme) (The SUN, 20.04.2020).

- KORUMA \& HIZMET: Türkiye'den kişisel koruma malzemeleri geldi mi? (Küçümseme) (The SUN, 21.04.2020). 
- FİASKO DEVAM EDIYOR Türkiye 'den getirilen 'Kullanışsız’ coronavirüs sağlık malzemeleri NHS sağlik testlerini geçemediğinden EL KONULDU (EleştiriKüçümseme) (The SUN, 07.05.2020).

- Royal Force uçağı Türk tedarikçi anlaşması krizi yüzünden bekliyor (Abart1) (The Telegraph, 22.04.2020).

- Birkaç saatte Türkiye'den gelebilecek olan yeterli miktardaki kişisel sağlık koruma malzemeleri gecikti (Abart1) (The Telegraph, 23.04.2020).

- Özel kaynak: Royal Air Force ile Türkiye'den getirilen sağlık koruma malzemeleri ‘kullanışsı' bulundu (Eleştiri- Küçümseme) (The Telegraph, 06.05.2020).

- 'Fiyasko' NHS için istenen kişisel sağlık malzemeleri gecikti (Eleştiri- Küçümseme) (Express, 19.04.2020).

- Türkiye den sağlık koruma malzemeleri NIHAYET büyük bir propagandayla ulaştı. (Eleştiri- Küçümseme) (Express, 22.04.2020).

- İşe yaramaz.' Türkiye 'den gönderilen 400.000 sağlık önlüğüne hükümet el koydu .(Eleştiri- Küçümseme) (Express, 07.05.2020).

- Başarısızlığa karşı Hayatı öneme sahip sağlık koruma kitleri için doktorların talepleri cevaba ulaşıyor. (İroni) (Mirror, 19.04.2020).

- Türkiye'den gönderilen kişisel sağlık koruma malzemelerinde fiyasko, onlar kullanılamaz. (Eleştiri- Küçümseme) (Mirror, 07.05.2020).

- Hayatı öneme sahip 400.000 önlük dahil kişisel sağlı koruma malzemeleri İngiltere ye gelişte gecikme (Eleştiri- Küçümseme) (The Guardian, 19.04.2020).

- Türk Sağlık Koruma Malzemeleri nihayet İstanbul havaalanından İngiltere'ye doğru yolda. (İroni) (The Guardian, 21.04.2020).

- Kişisel sağl1k koruma siparişi \%10`dan az depozitle İngiltere`de (İroni) (The Guardian, 23.04.2020).

- Hükümet, 400,000 Türk önlüklerinin NHS için kullanışsız olduğunu onayladı. (Eleştiri- Küçümseme) (The Guardian, 23.04.2020).

- Türkiye`den getirilen önlükler hükümetin son dakika stratejileriyle `kullanışsı` bulundu. (Eleştiri- Küçümseme) (Independent, 07.05.2020).

- İngiltere sadece Türkiye`den Pazar günü yardım istedi, Britons (İngilizler) onay1 sonrası yola çıktı. (İroni) (SKYNews, 21.04.2020).

- Ulusal Sağlık Sistemi için hayati önem taşıyan malzemelerin uçuşu ertelendi. (Abart1) (SKYNews, 21.04.2020).

\section{Bulgular}

Araştırmada elde edilen bulgulara göre Türkiye'nin yaptığı yardım Türkiye hakkında medya tarafından çizilen çerçeve ile ilişkili konumdadır. Ele alınan gazetelerde sık kullanılan kelimeler; "kullanışsız, Türk sağlık koruma malzemeleri, fiyasko, hayati önem, başarısızlık, erteleme, gecikme, güvenlik standardı, kriz, sağlık çalışanları” olarak görülmüştür.

Araştırmada ele alınan sağ politik ideolojiye sahip gazetelerde yer alan haber başlıklarının kelime seçimleri bu bağlamda oldukça dikkat çekicidir. Sağ siyasi akım çizgisinde ve Avrupa Birliği'ne karşı olan Express gazetesi bu durumu Türkiye nin propagandası olarak kaleme almıştır.

Türkiye ’nin bu yardımı propaganda aracı olarak kullandığını söyleyenlerin yanı sıra örneğin; Daily Mail gazetesi bu yardımı oldukça görünür kılmıştır. Bu durum hükümetin yetersiz 
politikalarına eleştiri olarak da değerlendirilmiştir. Ardından güvenlik testini geçemediği haberleri ise 'fiyasko' kelimesiyle manşetlerde yer almıştır.

Araştırmada incelenen sol siyasi akımına yakın gazetelerdeki haber başlıklarında Vital (Hayatı Önem), Finally (Nihayet), NHS Worker (Ulusal Sağlık İşçileri) kelimeleri başlıklarda kullanılmıştır ve bunun bir yardım olmasının yanı sıra belirli bir ücret karşıllı̆ında tedarikçi firmadan alındığı belirtilmiş, sağ kanat politikaya sahip hükümet yetersiz bulunmuştur. Bir şirket tarafından yönetilen Sky News ve kamu yayıncılı̆̆ 1 yapan BBC medyası ise daha sınırlı ve kontrollü tutum sergileyerek durumu yorum katmadan sunmayı yeğleyen bir haber dili kullanmaya özen gösterse de SKY News haber başlığında yer alan 'Britons (İngilizler) onayı sonrası yola çıktı' cümlesi dikkat çekicidir.

Genel olarak İngiltere basınında ikinci malzeme yardım gönderimi ve malzemelerin güvenlik testini geçemediği ile ilgili haberler geniş yankı bulmuştur; çünkü malzeme yardımı sürecinde yaşanan gecikme sağlık çalışanları tarafından hükümete yönelik tepkilere sebebiyet vermiştir. Kişisel sağlık koruma malzemelerinin olmaması nedeniyle sağlık çalışanları poşetlerle kişisel korumalarını sağlamak zorunda kalmıştır. Bu gecikmenin İngiltere ile Türkiye arasındaki tedarikçi firma nedeniyle olduğu bazı kaynaklardan söylense de bazı kaynaklar İngiltere kaynaklı olduğundan bahsetmiş bir haber kaynağında ise 'Britons' (İngilizler) izni sonrası ikinci yardım geldi gibi bir ibare kullanılmıştır.

Türkiye Büyükelçisi nin ibaresine (t.ly/XsLY) göre ise bu gecikmenin tamamen İngiltere bürokrasisi ile ilgili olduğudur. İncelenen haberler ile oluşturulan tabloların çerçevesinin basın ve siyaset arasındaki ilişkinin gündemi belirlerken önemli bir rolü olduğunu göstermektir. Haberlerin hepsi şunu göstermektedir; ilk yardım uçağının geç kalkması Türkiye ile ilgili bir durum değildir, yardımın gelmesinden sonra iki muhafazakâr parti parlamento vekilinin Twitter üzerinden teşekkürü yer almıyorken ardından güvenlik testlerini geçemediği haber dilinin çatışmacı söylemi ile sunulmuştur. Haberlerde bunun bir yardım olmadığı, ücret karşılığında alındığı da bir diğer vurgulama biçimidir.

Haber biçimlerinde belirtildiği üzere üçüncü yardım haberleri Guardian'dan BBC'ye, gazetelerden TV'lere tüm mecralarda yayınlanmış ve herkes Türkiye'den gelen ürünlerin 'işe yaramaz`olduğunu okuyup, izleyip, dinlemiştir. Sonrasında ise Birleşik Krallık Türkiye Büyükelçisi Dominick Chilcott Twitter hesabından bu suçlamaları yalanlasa da bu yalanlama sadece kişisel Twitter hesabından yapılan bir açıklama ile kalmış, bu suçlamanın yalanlaması ile ilgili olarak ele alınan yayın organlarında bir haber olmadığı bulgular arasındadır. BBC Türkçe`de ise (t.ly/idrw) bu tweetin haber olduğu tespit edilmiştir.

İngiltere Başbakanı Boris Johnson liderliğindeki Conservative (Sağ-Muhafazakâr) Parti, İngiltere ’nin son dönem Brexit süreci (Avrupa Birliğinden ayrılma) ve ardından Covid-19 politikaları nedeniyle medyanın eleştirilerinin odağındadır. Bu durum makro ve mikro yapı incelemesinde retorik ardalanda sağ-muhafazakâr ideolojiye sahip gazetelerin başlıklarında eleştiri- küçümseme ibarelerinin fazlaca olması ve tırnak içi kelime seçimlerinde eleştiriyi özellikle vurgulamaları da bulgular arasındadir.

Bu bakış gazetelerin Conservative (Sağ- Muhafazakâr) Parti ile aynı ideolojiye sahip olması, bunların da haberlerdeki yansıma biçimi görüldüğü üzere kişisel sağlık koruma malzemelerinin yetersizliği ve yeniden kullanım gibi bir açıklamanın mümkün olamayacağ gibi bir başlık ile dile getirilmiştir. Sol ideolojiye ve Liberal ideolojiye sahip gazeteler (Mirror, The Guardian, Independent) sağl1k koruma malzemelerinin aciliyeti, NHS işçilerinin zor durumunu sağ ideolojiye sahip gazetelere (Daily Mail, The SUN, The Telegraph, Express) göre daha öne çıkarmıştır. Bu bulgulardan yola çıkarak iç politikadaki sorunların dış politikayı da etkilediğini söylemek mümkündür. Haberlerde oluşturulan çerçeve ile hem iç politikadaki yanlışlara ilişkin bir çerçeve çizilirken diş politikaya yönelik çizilmiş olan imaj da devam ettirilmiştir. 


\section{Sonuç}

Haberlerin sunum biçimiyle verilen fotoğraf, haber başl1kları, noktalama işaretleri, yazım biçimleri üretilen haberlerin ideolojik çerçevesini göstermektedir. Araştırmanın temel problemi olan Covid-19 sürecinde Türkiye 'nin İngiltere’ye yardım gönderimi ile ilgili haberlerin nasıl yansıtıldığ söylem analizi ile sunum biçimleri ekseninde tespit edilmiştir. Bulgularda elde edilen sonuçlara göre, haber bir yayın kuruluşu için olumlu özellikleriyle ön plana çıarken, başka bir yayın kuruluşu için olumsuz yanlarılla gösterilmiştir. Haberin içeriği aynı olsa da çerçevelenme şekli ile haber biçiminde farklılıklar tespit edilmiştir. 10 Nisan-8 Mayıs 2020 tarihleri arasında İngiltere'de farklı ideolojilerle yayın yapan Daily Mail, The SUN, The Telegraph, Mirror, The Guardian, BBC, Independent, Sky News, Express gazetelerinde değerlendirmeye alınan 30 adet haber farklı sunum biçimleri ile gösterilmiş aynı ideolojik çerçeveye sahip haberler ise aynı sunum biçimi ile yansıtılmıştır. Bulgulardan yola çıkarak elde edilen sonuçlara göre üretilen haberler ideolojilerin etkisi altında kalarak belirli bir çerçeve eksenininde sunulmaktadır. Belirlenen sürede incelenen haberlerin yansıtılma şeklinden yola çıkarak gazetelerin ideoloji ve hakim güçlerin etkisinde kaldığı, haberi üretirken gerçeği de yeniden üretip anlamlandırdığı, politikanın Covid-19 sürecinde de haberlerde aktif ve yanlı olarak kullanıldığı, şartlar ne olursa olsun basın kuruşlarının haberleri iktidarın lehine ya da aleyhine kullanabileceği, kendi yayın politikalarına bağlı olarak haberi çerçevelendirip okucuizleyici kitlesine sundukları sonucuna ulaşılmıştır.

\section{Kaynakça}

Arık, B. (2009). İnsan ve Toplumu Bir Arada Düşünmedikçe Popüler Kültürü Tartışamayız, Medya ve Popüler Kültür Eleştirel Bir Yaklaşım, (Der.) E. Karakoç. Literatürk Academia, 1-30.

Atabek, N. ve Uztuğ, F. (1998). Haberde Çerçeveleme ve Öne Çıkarma, Anadolu Üniversitesi İletişim Bilimleri Fakültesi Kurgu Dergisi, 15 (1), 96-105.

Bilgin, N. (2003). Sosyal Psikoloji Sözlüğü, Kavramlar, Yaklaşımlar. Bağlam Yayınları.

Bingül B. \& Türk A. \& Ak R.(2020). Covid-19 Bağlamında Tarihteki Büyük Salgınlar ve Ekonomik Sonuçları, Turkish Studies, 15(4), 190-200. http://dx.doi.org/10.7827/TurkishStudies.44348

Burton, G. (1995). Görünenden Fazlası. (Çev.) N. Dinç, Alan yayınları.

Bulut, S. (2020). Egemen Söylemin Klylsindakiler: Alternatif Bir Platform Olarak Youtube'da Gazetecilik ve Gazetecilik Üzerine Bir İnceleme, Erciyes İletişim Dergisi, 7(2), 727- 748.

Çapl1, B. (2002). Medya ve Etik. İmge Kitabevi.

Devran, Y. (2010). Haber, Söylem, İdeoloji, Başlık Yayın Grubu.

Dursun, Ç. (2001). Televizyon Haberlerinde İdeoloji. İmge Yayınevi.

Eagleton, T. (1996). İdeoloji, (Çev.) Özcan M., Ayrıntı Yayınları.

Erdoğan, İ. (1997). İletişim Egemenlik Mücadeleye Giriş. İmge Yayınları.

Erdoğan İ. \& Alemdar, K. (1998). İletişim Kuram ve Araştırmaları. My Yayınları.

Herman, E. S \& Chomsky, N. (1998). Medya Halka Nasıl Evet Dedirtir. (Çev.), Akyoldaş, B. ve Han, T. Minerva Yayınları.

İnal, A. (1994). Haber Metinlerine Eleştirel Bir Bakış: Temel Sorunlar ve Örnek Çalışmalar, A.Ü. İletişim Fakültesi, 135-163.

İnal, A. (1996). Haberi Okumak. Temuçin Yayınları. 
İnceoğlu, G.Y \& Çomak, A.N. (2009). Teun A. Van Dijk, Metin Çözümlemeleri, (Der.) Y.G. İnceoğlu ve N. A. Çomak. Ayrıntı Yayınları, 19-83.

Karaduman, S. (2017). Eleştirel Söylem Çözümlemesinin Eleştirel Haber Araştırmalarına Katkısı ve Sunduğu Perspektif, Maltepe Üniversitesi İletişim Fakültesi Dergisi, 4(2), 31-46. https://dergipark.org.tr/en/download/article-file/386936

Mumby, K. D. (2004). İdeoloji ve Anlamın Toplumsal İņ̧ası: Bir İletişim Bakış Açısı, (Çev.) Ç. Dursun, Doğu Batı İdeolojiler-3, 30.

Özerkan, Ş. (2002). Medya, Dil ve İdeoloji. İstanbul Üniversitesi İletişim Fakültesi Dergisi, 1(12), 63-76.

Özkır, Y \& Şişman, B. (2014). Soma Maden Kazasının Internet Gazetelerinde Aktarılmasının Haberde İdeoloji Bağlamında Değerlendirilmesi, Iğdır Üniversitesi Sosyal Bilimler Dergisi, 6, 65-81.

Scheufele D. A. ve Tewksbury D. (2007). Models of Media Effects, Journal of Communication 57 9-20, International Communication Association. 15.

Shoemaker, P. \& Reese, S.D. (1997) İdeolojinin Medya İçeriği Üzerindeki Etkisi, Medya Kültür Siyaset, (Der.) S. İrvan, Ark Yayınları, 99-136.

Sözen, E. (1999). Söylem: Belirsizlik, Mübadele, Bilgi, Güç ve Refleksivite. Paradigma Yayınları.

Şentürk, Acar, Z. \& Tos O. (2018). Íkinci Düzey Gündem Belirleme Araştırmast: 29 Ekim 2018 Günü Ulusal Gazeteler Örneği, Akademik Sosyal Araştırmalar Dergisi, 6 (85), 81-103. https://asosjournal.com/DergiTamDetay.aspx?ID=14517

Tokgöz, O. (2000). Temel Gazetecilik. İmge Kitabevi.

Toruk İ. \& Sine R. (2012). Haber Söylem Üretimindeki İdeolojik Etki: Wikileaks Haberleri, Selçuk Üniversitesi Türkiyat Araştırmaları Dergisi, 31, 361-378. https://dergipark.org.tr/tr/download/article-file/258391

Ülkü, G. (2004).Söylem Çözümlemesinde Yöntem Sorunu ve Van Dijk Yöntemi, Haber Hakikat ve İktidar İlişkisi, (Der.) Ç. Dursun, Elips.

Van Dijk T.A. (1988) News as Discourse, Lawrence Earlbaum Associates Publication.

Yağlı, S. (2007). Haber İdeoloji İlişkisi: Haber Metinlerinde Gerçekliğin Sunumu, Ege Üniversitesi İletişim Fakültesi Düşünceler Dergisi, 1, 355-366.

Yüksel E. ve Gürcan, H İ. (2005). Haber Toplama ve Yazma, Tablet Kitabevi. 